\title{
Evaluation of Seedling Size Following Germination Using Computer-aided Analysis of Digital Images from a Flat-bed Scanner
}

\author{
Robert L. Geneve ${ }^{1}$ and Sharon T. Kester \\ Department of Horticulture, University of Kentucky, Lexington, KY 40546
}

\begin{abstract}
Additional index words. seeds, seed testing, vigor, vigor testing, Brassica oleracea, Lycopersicon esculentum, Capsicum annuum, Impatiens walleriana, Catharanthus roseus, Tagetes patula
\end{abstract}

\begin{abstract}
Early seedling growth rate can be used to estimate seed vigor for small-seeded vegetable and flower seeds. However, hand measurement of small seedlings is tedious and difficult to reproduce among analysts. Computer-aided analysis digital images of seedlings should improve accuracy and reproducibility. A flat-bed scanner fitted with base and top lighting provided high resolution images of even small-seeded species like petunia [Petunia xhybrida 'Blue Picotee' (Hort) Vilm.] and lisianthus [Eustoma grandiflorum 'Mariachi Pure White' (Raf.) Shinn]. Uniform lighting was provided and images were captured and analyzed in less than 2 minutes. A clear, cellulose film was used as the germination substrate in petri dish germination assays to facilitate capturing images with a flat-bed scanner. The transparent medium permitted seedlings to be imaged without removal from the petri dish and also allowed for repeated measures of the same seedlings in order to calculate growth rate. Six species evaluated in this study included cauliflower (Brassica oleracea L., var. Botrytis), tomato (Lycopersicon esculentum Mill. 'New Yorker'), pepper (Capsicum annuum L. 'North Star'), impatiens [Impatiens walleriana Hook. f. 'Impact Lavender'], vinca [Catharanthus roseus (L.) G. Don. 'Little Bright Eye'], and marigold (Tagetes patula L. 'Little Devil Flame'). For germination and early seedling growth, the cellulose film compared favorably with other standard germination media (blue blotter and germination paper) for five of the six species tested. Computer analysis of seedling length was possible for all six species and was statistically similar to hand measurements averaged for three analysts.
\end{abstract}

Seed vigor is an important aspect of seed quality. Unlike standard germination tests, which are a required for each commercial seed lot, seed vigor tests attempt to provide an assessment of germination performance under field (Association of Official Seed Analysts, 1983) or greenhouse conditions. Although numerous seed vigor tests have been developed, five major ones are used by most seed analysts. These include accelerated aging, cold test, cool test, electrolyte leakage and seedling growth rate (Hartmann et al., 1997). Of these, accelerated aging and cold test account for the majority of vigor tests for agronomic crops (Ferguson Spears, 1995).

Received for publication 16 Aug. 2000. Accepted for publication 2 Nov. 2000. Univ. of Kentucky, College of Agriculture journal number 00-11-77. We thank Patchara Wonprasaid and Kay Oakley for their technical assistance. Seeds for this study were generously supplied by Ball Seed, Sakata Seed America, and Goldsmith Seeds. This research was partially funded through a grant from the Gloeckner Foundation. The cost of publishing this paper was defrayed in part by the payment of page charges. Under postal regulations, this paper therefore must be hereby marked advertisement solely to indicate this fact.

${ }^{1}$ To whom requests for reprints should be addressed. E-mail address: rgeneve@ca.uky.edu
Seed vigor tests used to evaluate largeseeded agronomic crops are generally not useful for evaluating smaller-seeded vegetable and flower species. In a standard accelerated aging test, rapid water uptake by small seeds may result in high mortality unrelated to the vigor of the seed. The accelerated aging test has been adapted to evaluate flower seeds by replacing water with saturated salt solutions $(\mathrm{KCl}$ or $\mathrm{NaCl})$ to keep moisture content in the seeds below 25\% (Jianhua and McDonald, 1996). Termed the saturated salt accelerated aging test, it has been used successfully to evaluate seed vigor in impatiens. This is an important development for vigor assessment in flower seeds and with further research could be adapted for other flower species.

The cold test, as currently conducted for agronomic crops, involves imbibing seeds at low temperatures $\left(10\right.$ to $\left.15^{\circ} \mathrm{C}\right)$ in a sterile or nonsterile field soil, or in other media for several days prior to a standard germination test. Studies on small-seeded crops are limited, but the nonsterile conditions of this test were not tolerated by black-eyed Susan (Rudbeckia fulgida L.) seeds (Fay et al., 1993). A cold test without soil may prove a useful alternative, but could be confounded in some species where dormant seeds could benefit from the cold treatment, leading to higher germination percentages than for control seeds.
Cool temperature germination $\left(<15^{\circ} \mathrm{C}\right)$ as a stress test may be a useful alternative for selected small-seeded crops.

Seedling growth rate tests can also be used to assess vigor in seeds. Ball Seed (Chicago) developed a vigor index by using a video camera to capture digital images of emerged seedlings in a plug tray to determine cotyledon area (Conrad, 1999). This has proven to be very successful in a limited number of bedding plant species. However, it relies on seedling emergence under greenhouse or growth chamber conditions. This limits its usefulness as a general vigor test for the industry, where greenhouse conditions vary with location or time of the year. The significant amount of space required to evaluate seedlings in plug flats would be limiting for evaluation of many species and seed lots.

One alternative is to measure seedling or radicle length in plants grown under controlled environments as an indicator of seed vigor. Evaluating seedling growth rate, especially radicle growth under controlled conditions, has been used successfully to test vigor in a number of small-seeded vegetable crops, including carrot (Daucus carota L.), lettuce (Lactuca sativa L.) (McCormac et al., 1990; Smith et al., 1973), radish (Raphanus sativus L.), sugar beet (Beta vulgaris L.) (Perry 1981), cauliflower (Brassica oleracea L. Botrytis Group), onion (Allium cepa L.) and leek (Allium ampeloprasum Tausch.) (Finch-Savage, 1986). Radicle length or growth rate, measured by using a slant-board test, was correlated with field emergence in these crops. These studies and others have established a strong correlation between radicle growth and the vigor level of a seed lot (Bingham et al., 1994). One problem with the slant-board test is that it is time consuming for the analyst to evaluate radicle length by hand and it can introduce analyst error in measuring radicle length.

McCormac et al. (1990) attempted to use digital image analysis of radicle length of small-seeded vegetable crops using the slantboard test. Although this was an accurate measure of radicle length, problems with lighting and background color made it difficult to evaluate the small roots of these crops. Paradigm Research Corp. (South Haven, Minn.) developed an improved digital camera system that has better control of lighting and contrast between the seedling and background and uses standard petri dish germination test conditions (D. McNertney, personal communication). Several other researchers have tried to automate this type of vigor test using machine vision (Howarth and Stanwood, 1993), timesequence photography (Tomas et al., 1992), and computerized automated seed analysis with a hand potentiometric caliper (Keys et al., 1984). The results of tests have correlated well with those of hand measurements of radicle length, but have failed to become routine tests used by commercial analysts for a variety of reasons related to standardized conditions for collected images used by the computer.

A good vigor test should be: 1) reproducible from lab to lab and analyst to analyst; 2 ) 
correlated with field or greenhouse emergence tests; 3) be rapid, objective and simple; and 4) inexpensive. The objective of this research was to develop a computer-aided evaluation system using digital images of radicle emergence that would be suitable for use as a vigor test. Key aspects developed for this research include the use of a flat-bed scanner to obtain digital images and evaluation of a transparent germination medium to facilitate scanning.

\section{Materials and Methods}

Plant material. Six small-seeded species (cauliflower, tomato, pepper, impatiens, vinca, and marigold) were evaluated for germination on three different germination media. Petunia and lisianthus were included to evaluate the ability to image and measure very small-seeded species.

Germination conditions. Twelve seeds per species were sown in 8.5 -cm-diameter plastic petri dishes containing either one piece of blue blotter (Anchor Paper Co., St. Paul, Minn.), two pieces of germination paper (Hoffman Manufacturing Co., Albany, Ore.) or one piece of a clear, uncoated cellulose film (CeloreyPUT, Cydsa Monterrey, Mexico). This film is transparent, absorbs water readily, and is $31.3 \mathrm{~mm}$ thick with a tensile strength of 1268 $\mathrm{kg} \cdot \mathrm{cm}^{-2}$. The cellulose film was cut to fit the petri dish, soaked in distilled water for $30 \mathrm{~min}$ to remove surface contamination, and autoclaved for $15 \mathrm{~min}$ to eliminate microbes from the film. Water $(1.5 \mathrm{~mL})$ was added to the dish prior to placing seeds on the film. For the blue blotter and germination paper, 5.25 or 4 $\mathrm{mL}$ of water was added, respectively. These quantities of water saturated the medium, leaving a thin layer of free water on the surface. Characteristics of water-holding ability were evaluated for each medium by measuring initial dry weight and subsequent water-saturated weight. Water uptake for a 60 -h imbibition period was also evaluated gravimetrically for tomato seeds on all three media. Petri dishes were sealed with Parafilm ${ }^{\circledR}$ (American National Can, Menasha, Wis.) and placed in a single germination chamber held at a constant $23{ }^{\circ} \mathrm{C}$ at $40 \mu \mathrm{mol} \cdot \mathrm{s}^{-1} \cdot \mathrm{m}^{-2}$ from cool-white fluorescent lamps.

Evaluation of seedling growth. Seedling growth was evaluated either by hand using a ruler, or using computer-aided analysis of digital images. Three analysts separately evaluated the same set of seeds. Petri dishes were refrigerated $\left(5^{\circ} \mathrm{C}\right)$ between hand and digital image acquisition. Each species was evaluated $2 \mathrm{~d}$ after initial radicle emergence. Digital images were acquired using a flat-bed scanner (Hewlett Packard Scanjet 4c/t; Palo Alto, Calif.) that included both base and top lighting. Scans were made for seeds on the cellulose film through the petri dish with the lid removed. Each scan created a 300 dpi (118 dots per $\mathrm{cm}$ ) resolution, black and white image. Seedling length was measured automatically using MacRhizo software (Regent Instruments, Quebec) set with a threshold between 180 and 205 depending on the size of each species.
Data presented for seedling growth on each germination medium was from a single analyst, while data presented for analysis method used seedlings on the film medium. A total of 60 seeds (five petri dishes) were evaluated for each treatment and analyzed using Tukey's test with petri dish as the experimental unit.

\section{Results and Discussion}

Cellulose film was an effective medium for growth of seedlings of all species except pepper (Table 1, Fig. 1). For tomato, impatiens, vinca, and marigold, there was no statistical difference between the blotter and cellulose film. Cauliflower seedling length was greater on paper and cellulose film compared to the blotter. In all species except pepper, growth on the cellulose film was statistically the same as or greater than that on the germi-

Table 1. Main effects of medium and method of measurement on data obtained for seedling length $(\mathrm{mm})$ measured $2 \mathrm{~d}$ after initial radicle emergence in six small-seeded crops.

\begin{tabular}{|c|c|c|c|c|c|c|}
\hline & \multicolumn{6}{|c|}{ Species } \\
\hline & Cauliflower & Pepper & Tomato & Impatiens & Vinca & Marigold \\
\hline Medium & \multicolumn{6}{|c|}{ Seedling length $(\mathrm{mm})$} \\
\hline Film & $10.2 \mathrm{a}^{2}$ & $6.9 \mathrm{c}$ & $10.9 \mathrm{a}$ & $7.5 \mathrm{a}$ & $5.6 \mathrm{a}$ & $20.0 \mathrm{a}$ \\
\hline Paper & $9.5 \mathrm{a}$ & $10.4 \mathrm{~b}$ & $7.5 \mathrm{~b}$ & $6.0 \mathrm{~b}$ & $5.8 \mathrm{a}$ & $21.8 \mathrm{a}$ \\
\hline Blotter & $8.1 \mathrm{~b}$ & $12.8 \mathrm{a}$ & $13.3 \mathrm{a}$ & $8.4 \mathrm{a}$ & $6.5 \mathrm{a}$ & $21.2 \mathrm{a}$ \\
\hline Method & \multicolumn{6}{|c|}{ Seedling length $(\mathrm{mm})$} \\
\hline Analyst \#1 & $8.5 \mathrm{c}$ & $6.5 \mathrm{a}$ & $11.6 \mathrm{a}$ & $6.1 \mathrm{~b}$ & $4.9 \mathrm{ab}$ & $16.9 \mathrm{~b}$ \\
\hline Analyst \#2 & $11.6 \mathrm{a}$ & $6.7 \mathrm{a}$ & $10.9 \mathrm{a}$ & $8.6 \mathrm{a}$ & $5.8 \mathrm{a}$ & $20.9 \mathrm{a}$ \\
\hline Analyst \#3 & $10.2 \mathrm{~b}$ & $6.9 \mathrm{a}$ & $10.9 \mathrm{a}$ & $7.5 \mathrm{a}$ & $5.6 \mathrm{ab}$ & $20.0 \mathrm{a}$ \\
\hline Computer & $10.7 \mathrm{ab}$ & $5.0 \mathrm{~b}$ & $11.7 \mathrm{a}$ & $8.6 \mathrm{a}$ & $4.8 \mathrm{~b}$ & $19.4 \mathrm{ab}$ \\
\hline
\end{tabular}

${ }^{2}$ Mean separation within columns and sets (medium, method) by Tukey's test, $P \leq 0.05$.

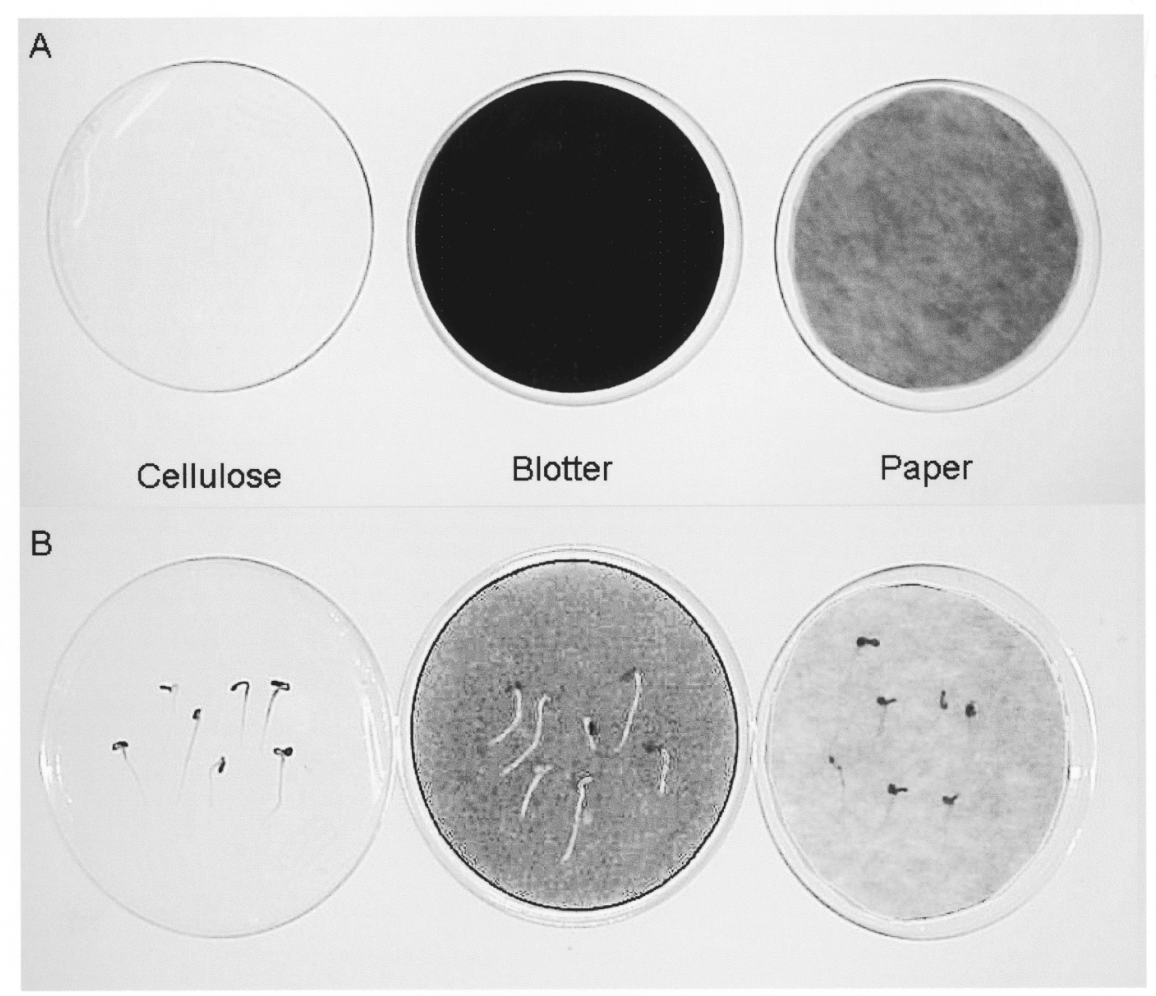

Fig. 1. Comparison of cellulose film, blue blotter, and paper as media for computer analysis of seedling growth. Panel (A) is back-lighted to show the degree of translucence for each germination medium. Panel (B) contains tomato seedlings and is illuminated from above. 
aging for vigor is important (Association of Official Seed Analysts, 1993).

The advantage of the cellulose film as a germination medium is that it is transparent, permitting digital images to be easily taken using a flat-bed scanner. In addition, it is compatible with standard germination conditions using a petri dish assay as performed by seed testing labs. In our studies, a slant board was not necessary to facilitate seedling length measurements as has been reported previously (Finch-Savage, 1986; McCormac et al., 1990). Improvements in analytical software allow for accurate measurements of the length of nonlinear objects and even compensate for seedling crossover. The flat-bed scanner used to capture digital images provided uniform lighting and software calibration would provide for repeatable results between labs.

The flat-bed scanner provided images of excellent resolution of even the smallest seeds and radicles (Fig. 3). Lisianthus is one of the smallest seeds $(22,000$ seeds per $\mathrm{g})$ grown by the bedding plant industry and hand measurements of early seedling growth in this species could not be performed easily. Capturing digital images of seedlings this small is difficult using digital camera technology. This is not a camera resolution problem, as resolution has improved in recent years and can be $1200 \mathrm{dpi}$ (472 dots per $\mathrm{cm})$. Flat-bed scanner resolutions have also improved to resolve more pixels per unit area, but we have not needed to increase the scanner resolution beyond 300 dpi (118 dots per $\mathrm{cm}$ ) to obtain usable digital images. The difference is that the digital camera is capturing images from as far away as 1 $\mathrm{m}$ from the seedlings. With the flat-bed scanner, the seedlings are closer to the imagecapturing device, accounting for the highquality images.

Recently, Dell'Aquila et al. (2000) studied imbibition using computer-aided image analysis. They employed a Charged Coupled Device (CCD-camera) rather than a flat-bed scanner and created a clear medium using $20 \mathrm{~mL}$ polymerized agarose in a petri dish. Their light source was an illumination table with fluorescent lamps under the petri dish. With this procedure, they were able to follow imbibition every $30 \mathrm{~min}$ for individual seeds. Although this system employs many of the same principles for capturing digital images presented in our study, we feel that the flat-bed scanner system offers several advantages. First, the light source is consistent and self-contained in the system. More importantly, the dual illumination from the scanner permits acquisition of images with the petri dish lid intact, regardless of condensation. In the previously cited study, condensation had to be controlled to acquire images. This required a double lid system with the air between the lids heated with a tungsten wire.

The length or area of each seedling can be calculated by computer-aided analysis using available software (Fig. 3). In our studies, MacRhizo was used to measure seedling length. This software is designed to measure root length and is not customized for measuring individual seedlings. However, the com-

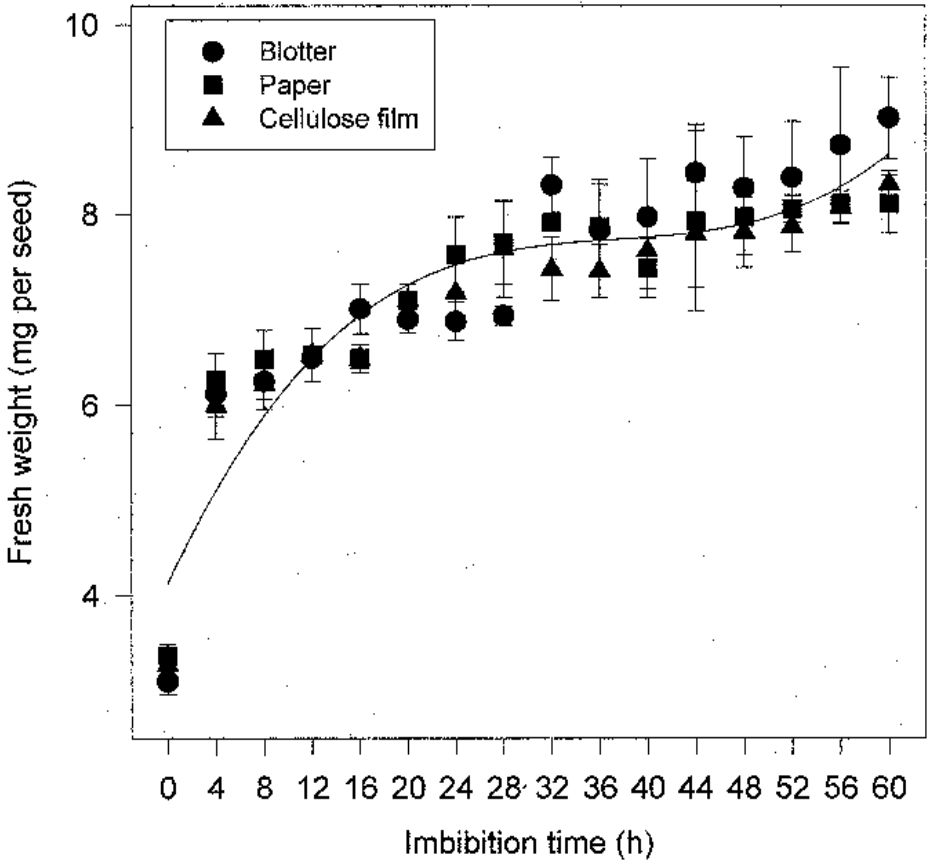

Fig. 2. Effect of germination medium on water uptake by tomato seeds during $60 \mathrm{~h}$ of imbibition. Error bars represent SE

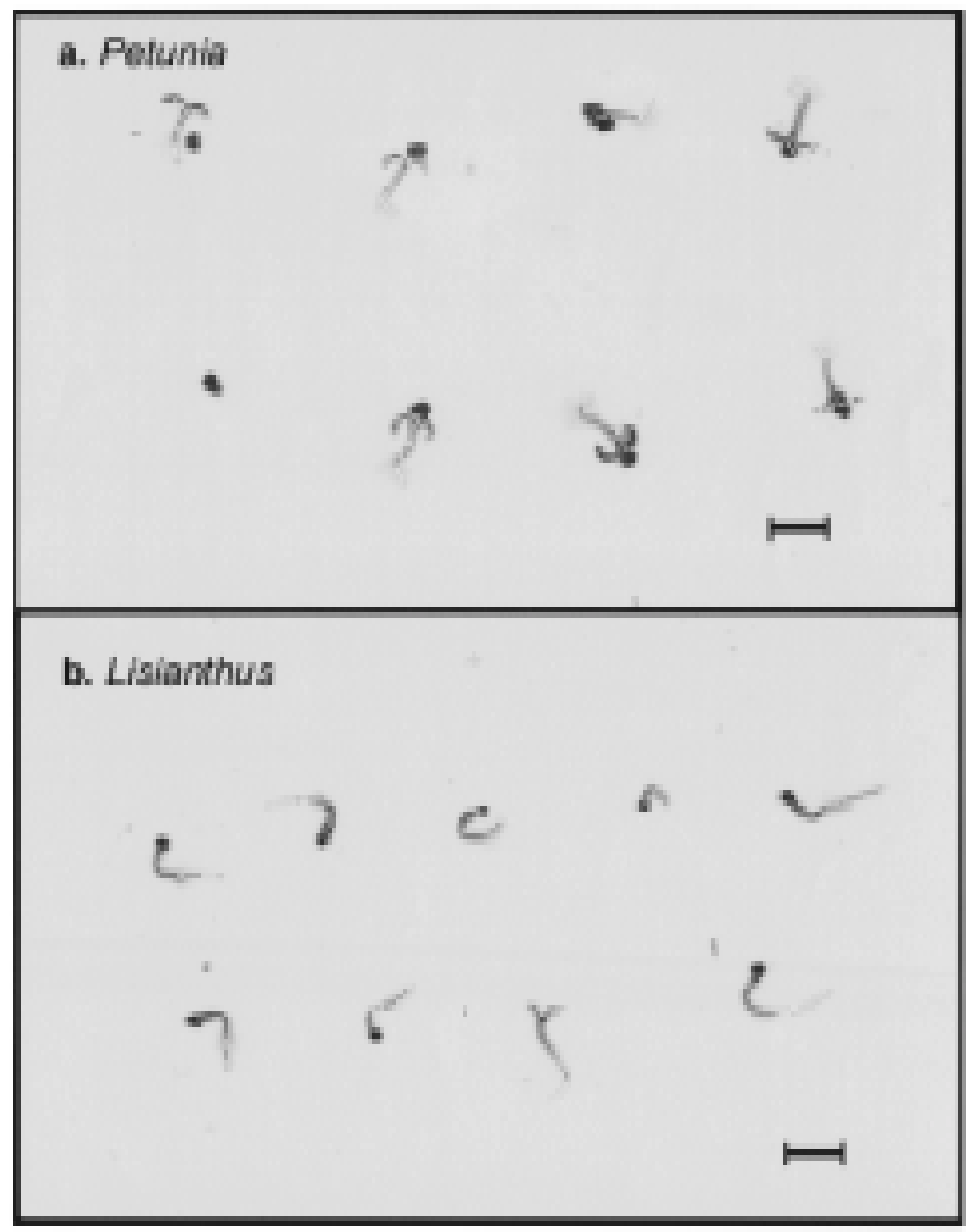

Fig. 3. Digital images taken with a flat-bed scanner at $300 \mathrm{dpi}(118$ dots per $\mathrm{cm})$ for (a) petunia and (b) lisianthus. Images were analyzed for seedling length using MacRhizo software that traces a line over the length of the image. Reference bars represent $5 \mathrm{~mm}$ for petunia and $2.5 \mathrm{~mm}$ for lisianthus. 
puter could detect and trace the length of small seedlings. Software is available that is customized for repeated measures of seedling length for vigor analysis and should be compatible with scanner-derived digital images (D. McNertney, personal communication).

There was no difference in seedling length when the same seedlings (data rounded to 1.0 $\mathrm{mm}$ ) were repeatedly scanned and measured using computer software, even when the petri dish was reoriented prior to scanning (data not shown). Therefore, hand measurements of seedling length by three analysts were compared with measurements obtained with MacRhizo software. Computer-assisted and hand measurements were not significant except for pepper (Table 1). More variation was evident among analysts than between analysts and computer-assisted length measurements. These data demonstrated the utility of using computer-aided analysis of seedling length, which also required a minimum of analyst time to perform. Each digital capture and computer-aided analysis required $<2$ min per petri dish and recorded data in spreadsheet format, saving additional time. Also, digital images can be archived in case a problem with a seed lot arises, and these could be reevaluated to provide evidence of the seed lot's initial quality.

In summary, a system has been developed for routine measurement of seedling length that could be used for seed vigor analysis. A flat-bed scanner was used rather than a digital camera to capture high quality images of even very small seeds. Use of the flat-bed scanner required the development of a clear germination medium and the cellulose film evaluated in this study provided a medium equivalent to standard opaque germination media currently used in seed analysis. The system described here is relatively inexpensive to set up and should allow for standardized testing among laboratories. However, it has yet to be determined whether seedling length can be used as a routine measure of seed vigor that has a meaningful relationship to seedling emergence in the field or greenhouse.

\section{Literature Cited}

Association of Official Seed Analysts. 1983. Seed vigor testing handbook. Contrib. No. 32. Assn. Offic. Seed Anal., Lincoln, Nebr.

Association of Official Seed Analysts. 1993. Rules for testing seeds. J. Seed Technol. 16:1-113

Bingham, I.J., A. Harris, and L. MacDonald. 1994. A comparative study of radicle and coleoptile extension in maize seedlings from aged and unaged seed. Seed Sci. Technol. 22:127-139.

Conrad, R. 1999. Method and apparatus for assessing the quality of a seed lot. U.S. Patent \# 5,901,237.

Dell' Aquila, A., J.W. van Eck, and G.W.A.M. van der Heijden. 2000. The application of image analysis in monitoring the imbibition process of white cabbage (Brassica oleracea L.) seeds. Seed Sci. Res. 10:163-169.

Fay, A.M., M.B. McDonald, and S.M. Still. 1993.
Vigor testing of Rudbeckia fulgida seeds. Seed Sci. Technol. 21:453-462.

Finch-Savage, W.E. 1986. A study of the relationship between seedling characters and rate of germination within a seed lot. Ann. Appl. Biol. 198:441-444.

Ferguson Spears, J. 1995. An introduction to seed vigour testing, p. 1-9. In: H.A. van de Venter (ed.). Seed vigor testing. Intl. Seed Testing Assn., Zurich, Switzerland.

Hartmann, H.T., D.E. Kester, F.T. Davies, Jr., and R.L. Geneve. 1997. Plant propagation: Principles and practices. $6^{\text {th }}$ ed. Prentice-Hall, Englewood Cliffs, N.J.

Howarth, M.S. and P.C. Stanwood. 1993. Measurement of seedling growth rate by machine vision. Trans. Amer. Soc. Agr. Engineers 36:959-963.

Jianhua, Z. and M.B. McDonald. 1996. The saturated salt accelerated aging test for small-seeded crops. Seed Sci. Technol. 25:123-131.

Keys, R.D., R.G. Margapuram, and G. A. Reusche. 1984. Automated seedling length measurement for germination/vigor estimation using a CASAS (computerized automated seed analysis system. J. Seed Technol. 9:40-53.

McCormac, A.C., P.D. Keefe, and S.R. Draper. 1990. Automated vigour testing of field vegetables using image analysis. Seed Sci. Technol. 18:103-112.

Perry, D.A. 1981. Handbook of vigour test methods. Intl. Seed Testing Assn., Zurich, Switzerland.

Smith. O.E., N.C. Welch, and T.M. Little. 1973. Studies on lettuce seed quality: I. Effect of seed size and weight on vigor. J. Amer. Soc. Hort Sci. 98:529-533.

Tomas, T.N., A.G. Taylor, and L.A. Ellerbrock. 1992. Time-sequence photography to record germination events. HortScience 27:372. 